\title{
Population Aging in the European Information Societies: Towards a Comprehensive Research Agenda in eHealth Innovations for Elderly
}

\author{
Mihaela Vancea ${ }^{1, *}$, Jordi Solé-Casals ${ }^{2}$ \\ ${ }^{1}$ Núcleo de Investigación Científica y Desarrollo Tecnológico en Ciencias Sociales y las Humanidades \\ Universidad de la Frontera, Chile \\ ${ }^{2}$ Data and Signal Processing Research Group, U Sciences Tech, University of Vic - Central University of \\ Catalonia, Spain
}

[Received September 26, 2015; Revised November 27, 2015; Accepted December 14, 2015]

\begin{abstract}
Population ageing is one of the major social and economic challenges of our contemporary societies. With the advent of the information society, new research and technological developments have been promoted in the field of assistive technologies and information and communication technologies of benefit to elderly people. This article examines the potentialities of new informatics developments in generating solutions to better address elderly people's daily-life, especially those with chronic illness and/or low autonomy. The authours attempt to propose a research agenda, by exposing various strengts and weaknesses of eHealth innovations for elderly, mainly grounded in secondary sources analysis.
\end{abstract}

Key words: elderly, eHealth, biometrics, health apps, independent living services, information and communication technologies (ICTs)

\section{Introduction}

Aging Population ageing has become one of the major social and economic challenges for the future of our societies. In 2014, around $18.5 \%$ of the total population were persons aged 65 and over in the EU-28's population, compared with data from 1991, when around $13.9 \%$ of the total population were persons aged 65 and over. Consistently low birth rates and higher life expectancy have come to transform the shape of the EU-28's age pyramid, a marked transition towards a much older population structure becoming prominent (http://ec.europa.eu/eurostat/statisticsexplained/extension s/EurostatPDFGenerator/getfile.php?file=146.83.207.82 1447872553_44.pdf; http://epp.eurostat.ec.europa.eu/ca che/ITY_OFFPUB/KS-EP-11-001/EN/KS-EP-11-001EN.PDF).

Besides persistently low fertility rates, strongly linked to the progressive inclusion of women in the labour market, the explanation for this demographic process lies, at least in part, in increasing life expectancies during recent decades due to improvements in the quality and availability of health care. Other factors such as increased awareness of health issues, higher standards of living, or changes in workplace occupations from predominantly manual labour to tertiary sector activities might also account for the increase in the proportion of elderly persons within the total population. As the proportion of people of working age in the EU-27 is shrinking and the relative number of those retired is expanding, an increasing burden will be put on persons of working age to provide for the social welfare services required by the ageing population http://epp.eurostat.ec.europa.eu/ cache/ITY_OFFPUB/KS-EP-11-001/EN/KS-EP-11-001EN.PDF) .

Contemporary societies are also characterised by a widespread dissemination and use of information and communication technologies (ICTs) in all spheres of life.

*Correspondence should be addressed to: Dr. Mihaela Vancea, Núcleo de Investigación Científica y Desarrollo Tecnológico en Ciencias Sociales y las Humanidades, Universidad de la Frontera, Chile. Email: mihaela.vancea@ ufrontera.cl.

Copyright: () 2016 Vancea M, et al. This is an open-access article distributed under the terms of the Creative Commons Attribution License, which permits unrestricted use, distribution, and reproduction in any medium, provided the original author and source are credited. 
Although most older people are in good health and perfectly capable of caring for themselves, a sizeable minority of those aged 70 and over have health conditions that require some sort of medical or personal assistance. Accordingly, new research and technological developments have been promoted in the field of assistive technologies and information and communication technologies of benefit of elderly and disabled people (http://ec.europa.eu/eurostat/statisticsexplained/extension s/EurostatPDFGenerator/getfile.php?file $=146.83 .207 .82$ 1447872553 44.pdf; http://epp.eurostat.ec.europa.eu/c ache/ITY OFFPUB/KS-EP-11-001/EN/KS-EP-11-001EN.PDF).

This article is based on an exploratory review of the role of eHealth technologies like Independent Living Services (ILSs), biometrics and health apps to improve the quality of life of elderly people so as to extend their participation in the European information societies, while acknowledging their possible limitations. In the following, we briefly describe our method and introduce the process of population ageing in European information societies. We then focus on particular eHealth solutions to promote an active and healthy ageing in the European societies, such as Independent Living Services (ILSs), biometrics and health apps. We examine their main functionalities and potential to preserve health and foster an independent and active lifestyle, and thus improve the quality of life of elderly people. We end the article with the final conclusions and suggestions for future research.

\section{Method}

In terms of situating the study, our analysis is intended to be relevant from both sociological and technological angles. We recognise the variety of disciplinary and paradigmatic perspectives employed for assessing eHealth technologies for elderly. These perspectives range in between strictly technical and more holistic approaches to the development of eHealth technologies. While we acknowledge the discrete value of these other paradigms and theoretical perspectives, our purpose is to conceptualise at a more general level. This level of conceptualization cannot be wholly free of theory, but we nonetheless consider that it is possible and even useful to generate conceptual frameworks at a more general level that allow for cross-theoretical and interdisciplinary understandings of the phenomenon under study.

To support our view of a general research agenda in eHealth innovations for elderly, we review key conceptual and empirical studies dealing with the strengths and weaknesses of eHealth technologies for elderly. The selection of studies is based firstly on the presence of explicit conceptual developments drawn from scientific database (ScienceDirect, PubMed, ResearchGate and
Google Scholar) search with the following keywords, and their respective combinations: population ageing, elderly/older people, eHealth, independent living services, assistive technologies, information and communication technologies, biometrics for health, health apps. Only English-language articles, books and reports were included in this review, from 1994 onwards. There was no intention to comprehensively review all studies relating to eHealth technologies for elderly. Rather, in addition to the explicit selection criteria above, we have sought to provide comparison across different eHealth technology types for elderly in terms of strengths and weaknesses. In particular, we examined studies relating to independent living services (ILS), biometrics for health and health apps. In the ILS area, the focus was exclusively on technologies that were computer-based or incorporated other aspects of ICTs. In biometrics for health, we focussed on technologies for indirect measurements of brain activity as we regarded them as quite challenging. In the apps area, given the widespread dissemination of mobile phone thecnology among all age groups, we included only health apps designed for mobile devices.

\section{Population ageing and e-health developments}

European countries are undergoing a significant change in their population structure as Europeans are living longer and healthier lives than ever before. The EU's population has started to age at a relatively fast pace. If the EU-27 median age increased from 35.4 years in 1991 to 41.2 years by 2011, by 2060 the median age of the EU-27 population is projected to rise to 47.6 years, around 7 years higher than in 2011. The share of the total EU 27 population older than 65 is expected to increase from 17.5 $\%$ in 2011 to $29.5 \%$ by 2060 (http://epp.eurostat.ec. europa.eu/cache/ITY OFFPUB/KS-EP-11-001/EN/KSEP-11-001-EN.PDF;http://eur-lex.europa.eu/legalcontent/EN/TXT/PDF/?uri=CELEX:52010DC0245R(01 $\stackrel{1}{ }$ from=EN).

Although people are now living longer, there has also been a significant increase in chronic illness such as heart disease, cancer and depression often linked to unhealthy lifestyles - tobacco use, physical inactivity, harmful use of alcohol and unhealthy diets - and also an increase in the level of morbidity. Most elderly people have at least one chronic illness; many face multimorbidity (i.e., have several chronic illnesses). Chronic illness can lead to severe and immediate disabilities like a hip fracture or a stroke, or to other progressive disabilities that may slowly diminish the ability of elderly people to lead an independent life and care for themselves (http://whqlibdoc.who.int/publications/2011/9789241502 283_eng.pdf) [2]. These ageing and illness patterns entail 
serious implications for public policies and budgets as demands for social protection and for social and health care services are exceeding the capacity of many European societies to respond effectively to this demographic change. Greater demands for treatment and care are leading to increased pressure on European societies' health and social care systems, making them financially unsustainable [2]. Changes in the demographic structure of the EU population are also impacting labour markets, families and individuals. Meanwhile, most of older people prefer to maintain their independence, so their demand for equal access to societal resources is becoming more and more assertive (http://epp.eurostat.ec.europa.eu/cache/ITY_OFFPUB/K S-EP-11-001/EN/KS-EP-11-001-EN.PDF) [2].

While many older Europeans lead active, healthy and participative lives well beyond their retirement into what is often referred to as the 'third age', others are faced with problems, such as poverty, illness or disability that can potentially confine their lifestyles. Various measures at the European level seek to address these challenges, including efforts to: promote the active participation of older persons in society; to provide accessible and effective healthcare services for the early detection of diseases and for helping elderly people to maintain their health and their independence; or to ensure that older persons have adequate incomes, generally through pension systems and support measures that aims to reduce the proportion of older persons that are at risk of poverty (http://epp.eurostat.ec.europa.eu/cache/ITY_OFFPUB/K S-EP-11-001/EN/KS-EP-11-001-EN.PDF).

Accordingly, the "active ageing" concept has been developed to define the process of optimising opportunities for health, participation and security in order to enhance quality of life as people age (http://whqlibdoc.who.int/hq/2002/WHO_NMH_NPH_0 2.8.pdf?ua =1). This definition encompasses the possibility of extending the activity of older persons within the labour force, through delaying their retirement, and also within society, through participation in a range of social, economic, civic or cultural activities. Besides basic measures of demographic change like gains in life expectancy, specific indicators to measure the propensity of older people to continue work, to participate in society and to lead an active retirement with a high quality of life should also be developed ( http://epp.eurostat.ec. europa.eu/cache/ITY_OFFPUB/KS-EP-11-001/EN/KSEP-11-001-EN.PDF).

The ageing of the European population and its serious effects on social security, pensions, long-term care, health care and family systems have also stimulated the development and implementation of specific digital tools as possible resources to improve or counter-act these outcomes [3]. Accordingly, considerable literature has appeared suggesting that eHealth and telemedicine innovations can play a significant role in promoting better health and independent living for elderly people, and in achieving sustainable health care systems across Europe $[4,5,6,7,8]$.

Quick access to health information and medical data can improve the knowledge basis in the health sector while making the delivery of care more effective. At the same time, health information and electronic access to medical data can also empower individuals. Well informed patients can use their medical data to preserve their health, self-manage health conditions, adopt healthy behaviours, and actively participate in clinical decisionmaking and medical treatment [2, 9]. Assistive Technologies (ATs) and Information and Communication Technologies (ICTs) may improve the situation of older adults and family caregivers [10]. Assistive social robots have positive effects in health care for the elderly with respect to mood, loneliness and social connections with others [11].

But the centrality of digital tools in many of the world's societies contrasts with the exclusion of individuals with limited or no access, use of, or knowledge of ICTs (the socalled digital divide) $[12,13]$. More than $50 \%$ of the European population uses Internet daily, though around $30 \%$ have still never used it at all (http://eurlex.europa.eu/legal-content/EN/TXT/PDF/?uri=CELEX: $52010 \mathrm{DC} 0245 \mathrm{R}(01) \&$ from $=\mathrm{EN})$. Since more and more daily tasks are carried out online, elderly people seem to face particular difficulties in benefiting fully from new digital content and services. Moreover, the digital divide between old and young individuals tends to be cumulative by gender, education and socio-economic status. For example, a recent longitudinal study conducted in the UK between 2002-2010 shows that although Internet access and use have increased over the period studied, both continue to be structured according to occupational class, educational background and age. As such, adults with lower levels of education, those older than 65 , and those working in manual jobs, were less likely to use the Internet for banking, purchasing, looking for work or accessing government services. Moreover, young, bettereducated respondents were more likely to have Internet access at home than those over 65 [14].

These findings show that besides increased ICTs access and use for underpriviledged groups like elderly people, enhanced digital skills are also required to fully take advantage of eHealth innovations and their potential to preserve health and foster a more independent and active life. Digital literacy would provide individuals with those skills necessary to understand and use ICTs and digital content and, thus, obtain all the benefits derived from this access and use [15, 16]. Beside, more knowledge about the technology needs of elderly people 
and how technology should best be designed would be needed in order for this to be effectively employed in everyday life.

In order to tackle the challenges posed by population ageing and the existing digital divide in contemporary information societies, the EU actively supports advanced technological research and development initiatives into specific health issues affecting elderly people as well as targeted e-inclusion initiatives and policies. As an example, the European Innovation Partnership for active and healthy ageing promoted by the European Commission aims to foster innovation as a way of increasing Healthy Life Years (HLY) by 2 years on average across the EU Member States [2, 17]. At the same time, the EU Digital Agenda with its Pillar VI aims to achieve a better distribution of ICT equipment and use, and thus tackle the digital divide at the European level (http://eur-lex.europa.eu/legal-content/EN/TXT/PDF/ ?uri=CELEX:52010DC0245R(01)\&from=EN).

There are authours who argue that, in light of an aging society, an effective delivery of healthcare should rely on technological innovations endorsing healthcare decentralisation, higher patient involvement and increased societal demands [18]. However, many eHealth technologies have not been very successful in achieving sustainable innovations in health and social care practices. As such, some authors claim that the current development of eHealth technologies often disregards the interdependencies between technology, human characteristics, and the socioeconomic environment, resulting in technology that has a low impact in health and social care practices. They thus promote a holistic approach to the development of eHealth technologies that takes into account the complexity of health and social care and the rituals and habits of interested individuals and other stakeholders [19].

Bioethicists express serious reservations about the long-term ethical and social consequences of various research initiatives in biotechnology. They react primarily to anti-aging interventions like regenerative medicine, stem-cell therapies, telomerase and efforts to mimic the effects of caloric reduction [20, 21, 22, 23]. Other authours suggest that in order to maximise the benefits associated with eHealth interventions and their potential to improve the health sector whilst minimising their risks, eHealth technologies should be evaluated during all their life course: during design, development and deployment stages [24].

In the same vein, other authours emphasise the gap that exists between the postulated and empirically demonstrated benefits of eHealth technologies. They suggest the need for more continuous and systematic research on the risks of implementing these technologies and thus evaluate their cost-effectiveness. Although, there is some evidence in relation to improvements in patient outcomes, the lack of evidence on their cost-effectiveness requires that future eHealth technologies are evaluated against a comprehensive set of measures, ideally throughout all stages of the technology's life cycle. Such evaluation should focus on socio-technical factors to maximise the likelihood of successful implementation and adoption [25].

\section{Independent living services (ILS)}

As individuals age, degenerative and chronic diseases become the leading causes of mortality and disability across Europe. These diseases are more common in the later life cycle and are costly for individuals, families and states. Yet, many of these diseases are preventable or at least postponable. In this context, policy measures and technological developments that promote supportive environments, active and healthy ageing, and independent living for elderly people have become crucial. Accordingly, within the European Comission's policy framework for innovative research in healthcare, ATs and ICTs are viewed as essential as they have the potential to provide high-quality, patient-centred and personalised health (social) care, while increasing the efficiency, safety and management of healthcare systems (http://ec.europa.eu/research/health/pdf/innovation-in-

healthcare-overview-report_en.pdf).

Independent Living Services (ILS) are generally defined as (culturally adapted) "enabling services" designed to help people to gain independence and help communities to eliminate barriers to independence. They refer to any product, application or service that enables people, whose independence in daily life is jeopardised, to lead a more independent and participatory life. Accordingly, ILS are particularly suitable for those individuals who have a physical impairment (physical, mental, cognitive, or sensory impairment) or face other economic or social barriers to independence, by allowing them to function independently in the community (http://ftp.jrc.es/EURdoc/JRC41496.pdf).

The ATs incorporate computer-based tools designed to allow elderly people to maintain their independence and improve mental health through the performance of tasks (i.e. ADLs), monitoring of behaviours (i.e. safety) and connection to support networks outside their place of residence [3]. ATs may provide older adults with an increased sense of safety and independence, allow them to remain in their homes longer, feel more actively involved in their care, decrease feelings of isolation and improve their overall sense of well-being [26].

Specifically designed ICT-based ATs like 'smart homes' and telemedicine can vary from basic systems involving the use of alarms and an ordinary telephone to 
intelligent monitoring with sensors and interactive communication. Smart home technologies within health and social care, for example, may include a wide range of ICT-enabled electronic assistive devices. These devices may operate in a stand-alone intelligent capacity to access, operate and control household appliances, or as integrated multiple devices leading to a technology-enriched home environment that facilitates and support the delivery of a range of health and social care services [27]. As such, smart home technologies seem to facilitate home management and everyday living for elderly people, by providing better and safer living conditions. They can be of great benefit particularly to elderly people who increasingly face mobility, vision, and hearing and cognitive performance difficulties (http://ftp.jrc.es/ EURdoc/JRC41496.pdf) [28].

Telemedicine and telecare offer medical care in the home, including ways of monitoring well-being and providing a secure home environment. Telemedicine has also the potential to broaden specialist access to a wider segment of population by reaching out to remote (or inaccessible) residential areas [9]. The integration of 'smart homes' and telemedicine may result in a more secure and autonomous living for elderly people, leading thus to better quality of life. New developments in Ambient Intelligence show how the whole environment (at home, on the move, in the street, whilst driving or during transportation, in public buildings and so on) could be equipped with embedded intelligence that helps individuals with everyday life (http://ftp.jrc.es/ EURdoc/JRC41496.pdf) [28].

ICT-based ILS refers to ICT products, applications and services based on the use of ICTs. There are already a variety of computer-based communication devices and applications such as e-mail and the World Wide Web (the internet) on the market that could help older people to live independently. Various research studies have shown that the use of ICTs may positively impact on the quality of life of older adults, by improving social support and psycho-social well-being [5, 6, 8]. For older adults who want to live at home, Internet access may improve connections with the outside world and help them avoid or reduce feelings of social isolation [4, 7]. Mobile telephony, e-mail and the Internet can help people with restricted mobility to actively participate in society. For instance, they can offer them opportunities for contact and communication with family members, relations and friends from abroad, or for civic and political participation.

ICT-based ILS can also facilitate contact between grandparents and grandchildren who live some distance away from each other, and between school children and elders via online education projects, and thus foster intergenerational relationships and cooperations. They are assumed to enhance a sense of community and combat alienation, like in the case of peer elder computer education programmes that enable their members to learn and teach others using computers and ICTs. Moreover, specific workplace technologies and tools can allow elderly people to work from home and thus prolong their working life (http://ftp.jrc.es/EURdoc/JRC41496.pdf).

ICT-based forms of carer support have health promoting effects also on elderly family carers since they enables them to gain more control over their perceived health due to increased knowledge and social contacts and support [29]. ICT-based interventions designed for elderly family carers provide carers with more flexible information, education and support, while they also enable carers to become part of the information society and in so doing help to reduce the digital gap. However, the combination of several approaches, both ICT-based and more traditional face-to-face support, seems to be more effective in supporting elderly carers of frail elderly people living at home $[29,30,31]$.

But ILS may also have negative effects usually related to the potential threat to users' privacy and autonomy posed by surveillance, personal data exposure, monitoring and other devices. However, there seems to be little ethical objection by the actual users of ATs, who are predominantly elderly people [32]. This might be explained by the fear of living in a nursing home, which most elderly people share $[33,34,35]$. ATs are viewed as being the least prohibitive method of protecting people, when compared to physically restrictive spaces with locked doors [36, 37]. Thus, the threat to users' privacy appears to be rather an issue of trade-offs [3]. Living at home seems to be more attractive and is traded off for any potential loss of autonomy and privacy, as these losses might be much bigger once the elderly people move to a nursing home $[33,34,35]$.

The limited access of older adults to ICTs and their reduced digital skills represents another significant challenge. Enhanced access for both practitioners and older adults should be thus advocated for promoting technology interventions [3]. Ethical arguments are raised primarily in respect to the autonomy and obtrusiveness (intrusiveness) aspects of ATs use [32, 38, 39]. The general view is that people are, or should be, independent and self-determinant, so many authours defend an individual approach in ATs use [40, 41]. Other authours argue whether this view is correct and helpful in the debate on ATs use in the care for (frail) elderly people [42, 43]. They instead support other ethical approaches that view people as social and reciprocal. This collective approach might be more appropriate for old people's caring and shed a different light on the ethical aspects of ATs use [32]. 
Based on the increasing evidence that ATs and ICTbased ILS seem to improve older people's communication with loved ones, reduce caregiver burden/stress, rise and support residence in own homes, policy-makers and practitioners should advocate for greater accessibility to and affordability of ATs and ICTs. Agencies and senior centres should consider how to provide opportunities and education programmes for older adults and their families to learn about technology. At last, as practitioners develop the capacity to incorporate AT and ICT interventions in care plans for elderly people, technology knowledge and use should be part of client assessment [3].

\section{Biometrics for health}

Biometric systems, given their potential to collect any kind of information about any biological organism or system, have been widely studied for their potential in security applications - indeed, most scientists and especially most laypeople largely think of biometrics in the context of fingerprint data, iris scanning and similar processes.

However, although these, along with computerized image processing of facial features, have been the basis of biometric security advances, collecting and using data about a specific person is not limited to them. Some new biometric programmes are now using information that is more abstract, what we might call "physical-behavioural" information, to identify a certain individual. An excellent example is the new development of a seat that can tell who is sitting in it by measuring the weight balances and other signals that come from a sensor-equipped pad showing data related to spinal alignment, body mass and balance and positioning tendencies. Another example is the capability of new smartphones, which have a built-in triaxial accelerometer, to capture information of person's walking gait to prevent falls in people with compromised balance, such as the elderly or those with Parkinson's disease [44].

These biometric advances bring technological devices ever closer to our hearts - literally - as well as to our eyes, skin and other organs. As such, biotechnology, or the integration of technology with the human body, is becoming more and more widespread.

\section{Cognitive impairments as an example}

Biometrics applications for individuals are quite diverse, the most important ones being related to individuals' health and safety. Although health and safety have traditionally been approached separately in biometrics, there are a variety of interactions between them.

With the increase in life expectancy, problems related to cognitive impairments become more important every day. Cognitive impairments become clearly visible by measuring behavioural biometric signals such as voice and writing. Moreover, individuals' ageing affects recognition rates of biometric security systems due to changes in the biometric signals that individuals experience as they age.

In health biometrics, it is important to have quantitative measurements to assess individuals' state of health. This applies especially to those diseases for which there are no biological markers and for which early diagnosis is difficult and is usually realised by examining individuals' cognitive abilities. In such cases, a computerbased analysis and signal processing can significantly improve assessments by health experts, since the latter are often more qualitative than quantitative.

In biometric measurements, the focus is on robust features that remain stable against changes in the state of health. Therefore, biometrics should be addressed from a global point of view taking into account the natural process of ageing in order to adjust the technological solution that can help in early detection of cognitive impairments. One such example is the research conducted by López-de-Ipiña et al. [45, 46, 47, 48] on improving the early diagnose of Alzheimer disease (AD) using continuous speech signal.

The researchers analysed non-invasive methods based on continuous speech and used them to design an automatic system that can offer medical doctors another point of view for the early diagnosis of AD. By analysing continuous speech, the system calculates an index whose values show whether the subject can be classified as being affected by $\mathrm{AD}$. Emotional Temperature (ET) is another parameter that, combined with other traditional speech parameters, can improve and facilitate the early diagnosis of $\mathrm{AD}[46,47]$. Recently, other nonlinear parameters like fractal dimension have demonstrated their validity as biomarkers to aid for $\mathrm{AD}$ early diagnosis [48]. The advantage of using spontaneous speech tests for the early diagnosis of $\mathrm{AD}$ is that these are not perceived as stressful. Moreover, the cost of speech analysis techniques is lower, as they do not require extensive infrastructure or the availability of medical equipment.

Handwriting signals have also been used for cognitive impairment detection. For example, some authors have examined information recovered by a graphical tablet, which provides up to 5 different parameters: azimuth angle, elevation angle, pressure, $\mathrm{X}$-coordinates and $\mathrm{Y}$ coordinates. Using these parameters, it is possible to design a classification system wherein the values of each parameter show the probability that an individual suffers from a specific cognitive impairment [49]. Online drawings performed by elderly people (control group) and $\mathrm{AD}$ patients were used in order to design a non-invasive system for dementia diagnosis. This system can also help 
medical staff to quantify their observations about how patients perform some written exercises or tests.

Another interesting example is the methodology developed by Drotar et al. [50] for building a predictive model of Parkinson's disease (PD) from kinematic handwriting features obtained from different conventional and novel handwriting tasks. PD is a progressively neurodegenerative disorder of variable chronology, for which e-health applications might result particularly appropriate, as a clinical course may run for more than 20 years with appropriate management [9].

Essential tremor is another common movement disorder, 20 times more common than Parkinson's disease. Around 50-70\% of esential tremor cases have a genetic origin. The Archimedes spiral drawing is one of the most used standard tests for its clinical diagnosis. Yet, nonlinear biomarkers based on entropy measurements from drawings and handwriting can be also used for an accurate diagnosis. This technological advancement has been crucial in this disorder since, as far as now the diagnosis has been based mainly on visual inspection and subjective interpretation of handwritting signals [51].

But early and more accurate diagnosis does not overcome the risk of being labeled as an 'ill' person and this decision may have serious social implications like stigma and discrimination. Researchers explain that when people are labelled as 'ill', though medical conditions may vary dramatically in the extent to which they are socially significant (compare hypertension, bone fractures and melanoma with for example incontinence, AIDS and schozofrenia), and linked to undesirable characteristics, a rationale is constructed for devaluing, rejecting and excluding them [52]. Although biologically conditioned, the concept of 'health' is strongly embedded in historical and social frames and its meanings are continually redefined in the social arena. Also stigma associated with a disease varies by time and space [53]. To identify an individual as 'ill' is not only a matter of physical or mental diagnosis, but also of redefining his or her social status.

\section{Mobile health applications for elderly people}

A radical change in disease and death patterns has occurred, closely related to the population ageing. Improvements in medications, rehabilitation and health systems have contributed to a delay in disability and death as well as to a shift from infectious and parasitic diseases to chronic and degenerative diseases, the so-called noncommunicable diseases. This global epidemiological change is more pronounced among the elderly, degenerative and chronic diseases being their primary diagnosis or cause of death (http://whqlibdoc.who.int/ publications/2011/9789241502283 eng.pdf). On the other hand, the growing fiscal and social burden of managing and preventing chronic diseases represents one of the greatest challenges facing our healthcare systems [54]. E-health can help meet this challenge by increasing efficiency in health care and thus decreasing costs, enhancing the quality of health care, and empowering individuals to actively manage their health and adopt healthy behaviours [9].

A wide range of health applications has been developed across the world in order to assist different user groups. Health applications are a technological tool that helps to inform and support people in the selfmanagement of their health and well-being. Some of these apps can prove extremely useful for elderly people in terms of self-empowerment and self-care. They may thus promote an active and healthy ageing and enhance the quality of life of this group of users. However, health apps need to be validated by practitioners and also by users in terms of their effectiveness in treating and solving particular health problems. Recent studies show that many health apps fail in their aim to support self-care because of problems related with inadequate navigation structures and search options and lack of feedback features [55]. As such, the design of health apps should be thought from the perspective of delivering healthcare with the aid of technology, rather than just a technological intervention.

The increased utilisation of mobile health apps provides an opportunity for doctors to integrate such technology into clinical practice. Yet, there is little medical professional involvement in their design and little regulation to improve accountability of app content [56]. In contrast to medical products for clinical use, for example, which experts have already certified, professional users have to decide on the appropriateness of health apps themselves. To enhance patient safety for health apps, a good information policy should always be part of the marketing strategy [57]. In this way, doctors could recommend and guide the use of health apps by their patients, and significantly enhance their medical attention with the support of emergent technologies or other innovative solutions in e-health. Elderly would in turn gain more confidence in using new technology and regard it as an additional solution to traditional medical care.

Elderly themselves are often neglected when developing or marketing a technological product, though they are the only growing age group in most European societies. They are however interested in mobile phones and services that deliver more social, active, meaningful and independent life [58]. Although older people are rather passive users of mobile phones and experience fear of consequences of using unfamiliar technology, the most preferred design features are aids for declining functional abilities [59]. Older users also present normally a lower navigation performance than younger users, but their 
performance tends to match younger users' when using mobiles with low complexity [60]. But rather than trying to teach older people how to use certain devices or health apps, we should probably evaluate the perceived added value of this technology and whether it can contribute to raising the quality of life of the end-user [61]. In the end, both patients and doctors should be well informed about the benefits, limits, and risks of an app in order to support their decisions whether they want to use it in a medical context or not [57].

Table 1. General Use Health Care Apps

\begin{tabular}{|c|c|c|c|}
\hline & Patients & Caregivers & Patients and caregivers \\
\hline $\begin{array}{l}\text { Accident and } \\
\text { Emergency/Addiction }\end{array}$ & $\begin{array}{l}\text { In Case of Emergency (Android, } \\
\text { Blackberry) }\end{array}$ & $\begin{array}{l}\text { BHF PocketCPR, ICE } \\
\text { (Android, Apple); Pocket } \\
\text { First Aid \& CPR (Android, } \\
\text { Apple);RCP \& Asfixia } \\
\text { (Android, Apple); } \\
\text { Trygfonden Hjertestart } \\
\text { [Tryg Foundation Heart } \\
\text { Start] (Apple); U-Turn } \\
\text { (Android, Apple) }\end{array}$ & 112 Iceland (Android, Apple) \\
\hline $\begin{array}{l}\text { Doctor-Patient } \\
\text { Communication }\end{array}$ & & & $\begin{array}{l}\text { Fodspor [Footprints] } \\
\text { (Apple, Android); Medipal } \\
\text { (Apple, Android); Tyze } \\
\text { (Apple) }\end{array}$ \\
\hline End-of-life issues & Legacy Organiser (Apple) & & $\begin{array}{l}5 \text { things to do before I die } \\
\text { (Facebook) }\end{array}$ \\
\hline Exercise & $\begin{array}{l}\text { Body Fitness Pro (Android); } \\
\text { CardioTrainer (Android); Global } \\
\text { Corporate Challenge (Apple, Android); } \\
\text { Healthy from O2 Health (Apple); Nike+ } \\
\text { Running (Apple, Android); Pedometer } \\
\text { (Apple, Android); Yoga Poses (Android) }\end{array}$ & & \\
\hline $\begin{array}{l}\text { General Healthcare } \\
\text { information }\end{array}$ & HealthTap (Apple, Android) & $\begin{array}{l}\text { IDoctus (web, iphone / } \\
\text { ipad, android) }\end{array}$ & FarmaciaPlus (Apple) \\
\hline $\begin{array}{l}\text { General Medical } \\
\text { Information }\end{array}$ & & & $\begin{array}{l}\text { mediLexicon (Apple, } \\
\text { Android); Speed Anatomy } \\
\text { Lite (Quiz) (Apple, } \\
\text { Android) }\end{array}$ \\
\hline Medical Records & & & $\begin{array}{l}\text { Capzule PHR (Apple); } \\
\text { MyMedRec (Apple) }\end{array}$ \\
\hline $\begin{array}{l}\text { Medication } \\
\text { Reminders }\end{array}$ & $\begin{array}{l}\text { Dosecast (Apple, Android); Dr.DRIN; } \\
\text { Med Minder (Android); OATBook } \\
\text { (Apple); Pill Reminder Pro (Push Notifi } \\
\text { cation) (Apple); Pillboxie (Apple); Refi } \\
\text { lls App (Apple); RxmindMe Prescription } \\
\text { (Apple) }\end{array}$ & & Pillbox (Apple) \\
\hline Pain & $\begin{array}{l}\text { My Pain Diary (Apple): Chronic Pain } \\
\text { Management (Apple, Android); Pain } \\
\text { Care }\end{array}$ & & \\
\hline Pharmacy finder & Apo-App (Android) & & \\
\hline Self Diagnosis & $\begin{array}{l}\text { iTriage (Apple, Android); WebMD } \\
\text { (Apple, Android). }\end{array}$ & & \\
\hline Sleep & Sleep Cycle Alarm Clock (Apple) & & \\
\hline Toilet finder & $\begin{array}{l}\text { Accessible Toilet Guide (Apple); } \\
\text { Porselensguiden [Toliet Guide] (Apple, } \\
\text { Android); Toilet Finder (Apple, } \\
\text { Android); Wheelmate (Apple) }\end{array}$ & & \\
\hline
\end{tabular}


Table 2. Diseases and Disabilities Apps

\begin{tabular}{|c|c|c|c|}
\hline & Patients & Caregivers & Patients and caregivers \\
\hline Alzheimer & $\begin{array}{l}\text { AlzNav (Android); Brain Map (Apple); BrainyApp (Apple); } \\
\text { Lumosity Brain Trainer (Apple) }\end{array}$ & $\begin{array}{l}\text { Alzheimer App (Android, } \\
\text { Apple); MobiCare } \\
\text { (Apple) }\end{array}$ & \\
\hline $\begin{array}{l}\text { Ankylosing } \\
\text { Spondylitis }\end{array}$ & Back to Action (Android, Apple) & & $\begin{array}{l}\text { iAnkylosingSpondylitis } \\
\text { (Apple). } \\
\end{array}$ \\
\hline Anxiety and stress & $\begin{array}{l}\text { Colour Therapy Anti Stress (Android); Headspace (on-the-go) } \\
\text { (Apple, Android); Live Happy (Apple); Stress Tips (Android, } \\
\text { Apple) }\end{array}$ & & \\
\hline Arthritis & $\begin{array}{l}\text { ArthritisID (Apple); Pauseboogie fra Gigtforeningen } \\
\text { (Android, Apple); RheumaTrack (Android, Apple); Tip Share } \\
\text { (Android, Apple) }\end{array}$ & & \\
\hline Asthma and Allergy & $\begin{array}{l}\text { MyAsthma (Android, Apple); Pollenvarsel (Android, Apple); } \\
\text { Sussex Air (Android, Apple) }\end{array}$ & & $\begin{array}{l}\text { AsthmaPulse (Apple); } \\
\text { AsthmaTrack (Apple) }\end{array}$ \\
\hline Cancer & $\begin{array}{l}\text { Borstkanker [Breast cancer] (Apple); Cancer iOncolex } \\
\text { (Apple); Ovarian Cancer Symptom Diary; Skin Scan (Apple); } \\
\text { UMSkinCheck (Apple) }\end{array}$ & & $\begin{array}{l}\text { Ecco CanCer (Android, } \\
\text { Apple) }\end{array}$ \\
\hline $\begin{array}{l}\text { Chronic fatigue } \\
\text { syndrome }\end{array}$ & ActiveME (Apple); CFSMapp (Android, Apple) & & \\
\hline $\begin{array}{l}\text { Communication } \\
\text { Disability }\end{array}$ & $\begin{array}{l}\text { HelpTalk (Android); Phrase Board (Apple);Predictable } \\
\text { (Apple); Proloquo2Go (Apple); SmallTalk Aphasia - Female } \\
\text { (Apple); SmallTalk Intensive Care (Apple); SmallTalk Pain } \\
\text { Scale (Apple); Speak it! Text to Speech (Apple); Talkforme } \\
\text { (Apple); Verbally (Apple) }\end{array}$ & & \\
\hline Continence & Bladder Pal (Apple, Android) & & \\
\hline Deafness & $\begin{array}{l}\text { Dragon Dictation (Apple); Hearing-Check (Apple); myFriend } \\
\text { Mobile (Android); Sorenson BuzzCards (Apple); SoundAMP } \\
\text { R (Apple); Subtitles (Apple); Tap Tap (Apple) }\end{array}$ & $\begin{array}{l}\text { Sign } 4 \mathrm{Me}-\text { a Signed } \\
\text { English Translator } \\
\text { (Apple) }\end{array}$ & \\
\hline Diabetes & $\begin{array}{l}\text { CarbFinder (Apple); Carbs \& Cals (Android, Apple); DAFNE } \\
\text { Online (Android, Apple); Diabetes UK Tracker (Apple); } \\
\text { OnTrack Diabetes (Android)Glucose Buddy_Diabetes } \\
\text { Helper (Apple); Glucose Companion Free (Apple); } \\
\text { HelpDiabetes (Android); iBGStar Diabetes Manager App } \\
\text { (mmol/L or mg/dL) (Apple); }\end{array}$ & & $\begin{array}{l}\text { Journals of the American } \\
\text { Diabetes Association } \\
\text { (Apple); }\end{array}$ \\
\hline $\begin{array}{l}\text { Disability/Disability } \\
\text { Mobility }\end{array}$ & $\begin{array}{l}\text { Body Language - Expressions (Android); Dragon Search } \\
\text { (Apple); Everyday Social Skills (Apple); Survival Signs \& } \\
\text { Words HD (Apple); Accessibility (Android, Apple); My } \\
\text { DisabledGo London (Apple); Wheelmap (Andorid, Apple) }\end{array}$ & & \\
\hline Fibromyalgia & FibroMapp (Android, Apple) & & \\
\hline Heart & $\begin{array}{l}\text { Blackouts Checkapp (Apple); iBP Blood Pressure (Android, } \\
\text { Apple); Instant Heart Rate (Android, Apple); Know Your } \\
\text { Pulse (Apple) }\end{array}$ & & $\begin{array}{l}\text { Blood Pressure Log } \\
\text { (Android) }\end{array}$ \\
\hline $\begin{array}{l}\text { Inflammatory Bowel } \\
\text { Disease }\end{array}$ & $\begin{array}{l}\text { Colonoscopy Prep Assistant (Android, Apple); myIBD } \\
\text { (Android, Apple). }\end{array}$ & & \\
\hline Kidney disease & $\begin{array}{l}\text { KidneyDiet (Android, Apple); RENAL TRKRR (Android, } \\
\text { Apple) }\end{array}$ & & \\
\hline $\begin{array}{l}\text { Mental health } \\
\text { problems }\end{array}$ & $\begin{array}{l}\text { Angry Birds (Andorid, Apple); Mobilplanforalle (Apple, } \\
\text { Android); Qcard (Appl); T2 Mood Tracker (Apple, Android). }\end{array}$ & $\begin{array}{l}\text { Buddy } \\
\text { (http://bit.ly/NjERtK) }\end{array}$ & $\begin{array}{l}\text { Cognitive Diary CBT } \\
\text { Self-Help (Android) }\end{array}$ \\
\hline $\begin{array}{l}\text { Neurological } \\
\text { conditions }\end{array}$ & & & $\begin{array}{l}\text { NeuroMind (Apple, } \\
\text { Android) }\end{array}$ \\
\hline Parkinson's disease & PD Life (Apple) & & Parkinsons (Apple) \\
\hline Stroke & FAST Test (Android, Apple) & & \\
\hline Visual Impairment & $\begin{array}{l}\text { BIG Launcher (Android); LookTel Money Reader (Apple); } \\
\text { VizWiz (Apple); Zoom Plus Video Magnifier (Android) }\end{array}$ & & $\begin{array}{l}\text { VisionSim by Braille } \\
\text { Institute (Apple) }\end{array}$ \\
\hline
\end{tabular}


One example of this possible communication or integration between health professionals and patients in terms of e-health might be the recent online plataform "Action for Healthy Ageing", the result of a European project on Active and Healthy Ageing (www.actionforhealthyageing.eu/en/default.php). This plataform aims to become a meeting point for all people interested in ageing. Accordingly, the online ecosystem provides information, training activities, digital tools, apps and many other resources for social inclusion agents, elderly people and the general population. It thus aims to promote active and healthy ageing as well as digital inclusion.

In this article, we focus on health apps designed for mobile devices. The exploratory review of existent mobile health apps helped us identify and classify useful and reliable apps for elderly people in order to promote an active and healthy ageing. We divided the reviewed apps into two categories: a) health apps of general use; and b) diseases and disabilities apps.

\section{Health Apps of general use}

The following apps are of general health care use. The main users can be: the patients (actual and potential); the social inclusion agents (family, friends, carers, medical professionals); and, in some case, both patients and social inclusion agents. These health apps may include different functionalities like:

- To improve communication, access patient's medical records or supply information on different symptoms or disabilities in case of accident or emergency

- To optimize doctor-patient communication

- To raise awareness of end-of-life issues

- To access general medical information and assist in navigating around basic health care issues

- To help improving attendance in consultation and offer medical guideline (pathologies, medications, dosages, interactions, dose calculation tools, diagnostic comparisons)

- To store, share and track medical records

- To help take medication on time and keep track of the medication

- To help manage pain and track medications, side effects, symptoms of pain and triggers

- To locate pharmacies in the user's local area and communicate directly with a chosen pharmacy, to enquire whether products are in stock

- To assist in diverse exercise activities

- To self-diagnose symptoms, find doctors and facilities and connect to hotlines

- To monitor movement and determine the lightest sleep phase for waking up
- To locate accessible toilets while travelling

\section{Diseases and Disabilities Apps}

Various apps focused on diseases and disabilities, while not explicitly designed for use by elderly people, may nonetheless prove important as some of these diseases or disabilities are specific to the third age. Most of these apps have been designed mainly for the use of patients (actual and potential) though there are also some intended for use by caregivers (e.g. family, friends, carers and medical professionals) or by both patients and caregivers. These apps may include different functionalities:

- To assist with diagnosis, treatment and care

- To help in travelling and moving about, for example, in the case of disability mobility

- To provide patient information

- To help detect, rate, track and improve disease/disability through self-monitoring like measuring reaction time, repetitive finger tapping, coordinated movement and exercise parameters in the case of Parkinson's disease

- To cope with society's attitudes to disease/disability, for example, in the case of chronic fatigue syndrome, communication disability, deafness etc.

- To improve communication, for example, in the case of communication disability, deafness or visual impairment

- To provide information on nutrition and diet, for example, in the case of diabetes, inflammatory bowel disease or kidney disease

- To help remember, manage and organize everyday lives, for example, in the case of mental health problems

- To help cope with daily living

- To offer support for symptoms and disabilities

An example of user interface app for Alzheimer's disease is presented in Figure 1, in which we show the screenshot of app's introduction, the list of activities and one game that users can play in order to help them live a brain healthy life.

\section{Conclusions and further research}

While the informatisation and technologisation of contemporary societies may have facilitated the integration of social and health care services, older people have been generally marginalised as digital users. In this article, we tried to assess the potential of different eHealth innovations like independent living services (ILS), biometrics and health apps for promoting an active and healthy ageing and well-being in the elderly population, 
while achieving the sustainability of existing health care systems.

Our exploratory review indicates that eHealth technologies have a significant potential in assisting the elderly in their everyday life and activities. They may promote an independent living by supporting basic activities (eating, bathing, toileting and getting dressed) and mobility (including navigation), providing household maintenance and early diagnosis and medical care of older people who need continuous attention, enhance social interaction and engagement, supporting physical and mental activity, etc.
ICT-based ILS could help older people to live independently and enhance their quality of life. They can offer them opportunities for contact and communication with family members, relations and friends from abroad, for civic and political participation, or for working from home. ICT-based ATs like 'smart' homes can make home management and everyday living much easier for elderly people, by providing better and safer living conditions. Telemedicine can offer medical care to the home, including ways of monitoring well-being and providing a secure home environment.

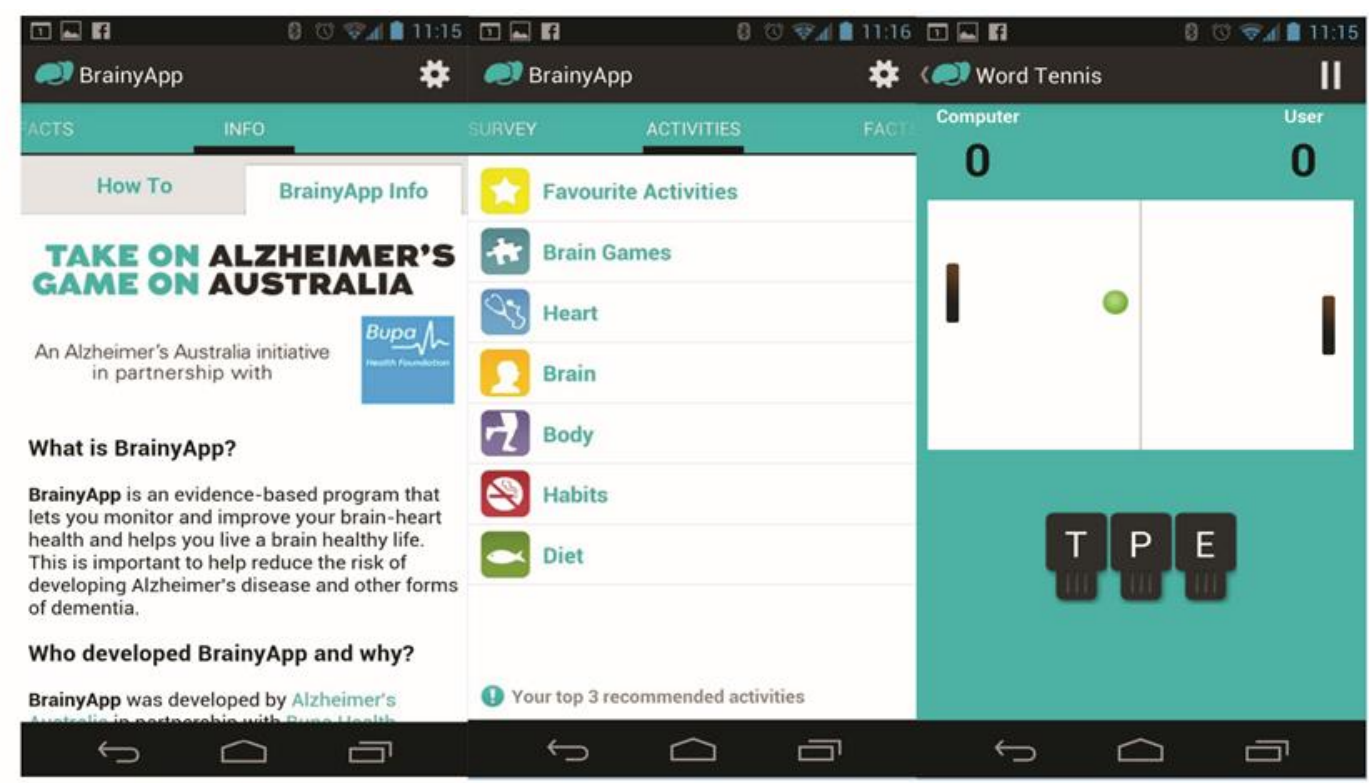

Figure 1. Screenshots of BrainyApp, one of the Alzheimer's disease apps listed in Table 2

Biometrics, originally used for biometric identification of individuals and thus devoted to security applications, may also be used in healthcare. The goal would be to identify health problems (risky situations, impairment, body features, etc.) that could be treated through innovative technological solutions. As such, specific technologies that analyse biometric traits like speech and handwriting or image processing and gait can help in identifying cognitive impairments. Biometric traits that significantly degenerate over time are not good candidates for healthcare digital applications, and neither are procedures that are uncomfortable for elderly people like, for example, retina scans.

Health apps could assist elderly people in managing their health, diseases and disabilities, but also caregivers and doctors in their daily activities with this segment of population. Health apps may have different functionalities to improve the health and living conditions of elderly people: from health apps of general use to apps focused on diseases and disabilities. Our list of revised health apps, even if not exhaustive, may provide valuable information on the target user groups and their main functionalities.

Possible limitations of eHealth technologies are mainly related with the digital divide and thus the exclusion of different population segments (among which, the elderly), loss of intimacy, surveillance exposure through access to personal data, market driven obsolescence of technological innovations, incongruity between users' needs and technology's functionalities, medical validation aspects, etc. Although eHealth technologies may be physically non-invasive, they collect 
a big amount of data, presumable stored in digital archives and easily exposed to public losses and this may be seen as an invasion to the person's intimacy. Some eHealth innovations may prove to be useless and thus imply wasted resources. There is also the feeling that, although eHealth technologies may improve the quality of life of elderly people, this will not occur automatically because a set of social, economic and political factors can drive these developments into different directions, leading even to a loss of quality of life.

Future research should focus on the effectiveness of eHealth technologies and the development of rigourous assessment criteria. We need more cross-disciplinary research that relates informatics and technology to different stages of the aging process and further studies to evaluate age and gender differences in eHealth access and use, quality of social and health care, economic factors and quality-of-life issues. This will allow us to assess the extent of exclusion of particular sub-groups like the elderly, who tend to possess lower levels of skills and access to computers and digital networks.

By focusing on different stages of the ageing process, we could better evaluate the technology needs of elderly people and how this technology should be best designed. Health apps should be specifically adapted to elderly people and include interactive features to enhance patients' self-care. A focus on the interactivity between different types of e-health technologies could offer innovative solutions to tailor new technologies to elderly people's preferred method of managing their health. Ehealth interactivity might also bring a shift in the way health professionals collaborate with patients, which should also be examined.

More research is also needed to examine hardware devices (cheap and easy to manage) that could allow increasing the type of recorded biosignals. The use of Arduino and Raspberry Pi could be explored in performing biometric and medical applications where body monitoring is needed. A variety of different sensors could be used in these devices, including sensors for pulse, the level of oxygen in blood (SPO2), airflow (breathing), body temperature, electrocardiogram (ECG), glucometer, galvanic skin response (GSR - sweating), blood pressure (sphygmomanometer) or patient position (accelerometer).

\section{Acknowledgements}

This work was supported by the European Union through the SEACW project (ICT-PSP-2012), and by the University of Vic - Central University of Catalonia under the grant R0947. The authors are indebted to ALIAD Conocimiento y Servicio for their comments and suggestions and would like to gratefully acknowledge them.

\section{References}

[1] Ballabio E, Whitehouse D (1999). Ageing and disability in the information society: a European perspective on research and technological development. Technology and Disability, 10:3-10.

[2] Dimitrova R (2013). Growth in the intersection of eHealth and active and healthy ageing. Technology and health care, 21:169-172.

[3] Blaschke CM, Freddolino PP, Mullen EE (2009). Ageing and Technology: A Review of the Research Literature. Br J Soc Work, 39(4): 641-656.

[4] White H, McConnell E, Clipp E, Bynum L, Teague C, Navas L, Craven S, Halbrecht H (1999). Surfing the Net in later life: A review of the literature and pilot study of computer use and quality of life. The Journal of Applied Gerontology, 18(3): 358-78.

[5] White H, McConnell E, Clipp E, Branch LG, Sloane R, Pieper C, Box TL (2002). A randomized controlled trial of the psychosocial impact of providing internet training and access to older adults. Aging and Mental Health, 6(3): 213-21.

[6] Czaja SJ, Lee CC (2003). The impact of the internet on older adults. In: Charness, N, Schaie, KW, editors. The Impact of Technology on Successful Aging. New York: Springer Publishing.

[7] Bradley N, Poppen W (2003). Assistive technology, computers and internet may decrease sense of isolation for homebound elderly and disabled persons. Technology and Disability, 15: 19-25.

[8] Eastman JK, Iyer R (2004). The elderly's use and attitude towards the internet. Journal of Consumer Marketing, 21(3): 208-20.

[9] Wicks P, Stamford JJ, Grootenhuis MA, Haverman L, Ahmed S (2014). Innovations in e-health. Quality of Life Research, 23: 195-203.

[10] Billipp SH (2001). The psychosocial impact of interactive computer use within a vulnerable elderly population: A report on a randomized prospective trial in a home health care setting. Public Health Nursing, 18(2):138-45.

[11] Broekens J, Heerink M, Rosendal H (2009). Assistive social robots in elderly care: a review. Gerontechnology, 8(2): 94-103.

[12] Castells M (2010). End of Millennium: The Information Age: Economy, Society, and Culture (Vol. 3). John Wiley \& Sons.

[13] van Dijk J. The network society (3rd ed.). London: Sage Publications Ltd; 2012.

[14] White P, Selwyn N (2013). Moving On-line? An Analysis of Patterns of Adult Internet Use in the UK, 2002 to 2010. Information, Communication and Society, 16(1): 1-27.

[15] Gilster P. Digital literacy. Wiley Computer Pub; 1997.

[16] van Dijk J, Hacker K (2003). The digital divide as a complex and dynamic phenomenon. The information society 19(4): 315-326. 
[17] Lagiewka K (2012). European innovation partnership on active and healthy ageing: triggers of setting the headline target of 2 additional healthy life years at birth at EU average by 2020. Archives of Public Health, 70(1): 23.

[18] Koch S, Hägglund M (2009). Health informatics and the delivery of care to older people. Maturitas, 63(3): 195199.

[19] van Gemert-Pijnen JE, Nijland N, van Limburg M, et al (2011). A holistic framework to improve the uptake and impact of eHealth technologies. Journal of medical Internet research, 13(4): e111.

[20] De Grey AD, Baynes JW, Berd D, Heward CB, Pawelec G, Stock G (2002). Is human aging still mysterious enough to be left only to scientists? BioEssays, 24(7): 667-676.

[21] Lin YJ, Seroude L, Benzer S (1998). Extended life-span and stress resistance in the Drosophila mutant methuselah. Science, 282(5390): 943-946.

[22] Helfand SL, Inouye SK (2002). Rejuvenating views of the ageing process. Nature Reviews Genetics, 3(2): 149-153.

[23] Partridge L, Gems D (2002). Ageing: a lethal side-effect. Nature, 418: 921.

[24] Catwell L, Sheikh A (2009). Evaluating eHealth Interventions: The Need for Continuous Systemic Evaluation. PLoS Med 6(8): e1000126.

[25] Black AD, Car J, Pagliari C, Anandan C, Cresswell K (2011). The Impact of eHealth on the Quality and Safety of Health Care: A Systematic Overview. PLoS Med 8(1): e1000387.

[26] Cheek P, Nikpour L, Nowlin HD (2005). Aging well with smart technology. Nursing Administration Quarterly, 29:329-338.

[27] Martin S, Kelly G, Kernohan WG, McCreight B, Nugent C (2008). Smart home technologies for health and social care support. Cochrane Database Syst Rev, (4): CD006412.

[28] Tang P, Venables T (2000). 'Smart' homes and telecare for independent living. Journal of Telemedicine and Telecare, 6(1): 8-14.

[29] Torp S, Hanson E, Hauge S, Ulstein I, Magnusson, L (2008). A pilot study of how information and communication technology may contribute to health promotion among elderly spousal carers in Norway. Health \& social care in the community, 16(1): 75-85.

[30] Schulz R (2001). Some critical issues in caregiver intervention research. Aging and Mental Health, 5 (Suppl. 1):112-115.

[31] Czaja SJ, Rubert MP (2002). Telecommunications technology as an aid to family caregivers of persons with dementia. Psychosomatic Medicine, 64: 469-476.

[32] Zwijsen SA, Niemeijer AR, Hertogh, CMPM (2011). Ethics of using assistive technology in the care for community-dwelling elderly people: An overview of the literature. Aging \& Mental Health, 15(4): 419-427.

[33] Essen A (2008). The two facets of electronic care surveillance: An exploration of the views of older people who live with monitoring devices. Social Science and Medicine, 67: 128-136.
[34] Levy S, Jack N, Bradley D, Morison M, Swanston M (2003). Perspectives on telecare: The client view. Journal of Telemedicine and Telecare, 9:156-160.

[35] Mihailidis A, Cockburn A, Longley C, Boger J (2008). The acceptability of home monitoring technology among community-dwelling older adults and baby boomers. Assistive Technology, 20: 1-12.

[36] McShane R, Hope T, Wilkinson J (1994). Tracking patients who wander: Ethics and Technology. The Lancet, 343: 1274.

[37] Miskelly F (2004). A novel system of electronic tagging in patients with dementia and wandering. Age Ageing, 33: 304-306.

[38] Courtney KL, Demiris G, Hensel BK (2007). Obtrusiveness of information-based assistive technologies as perceived by older adults in residential care facilities: A secondary analysis. Medical Informatics and the Internet in Medicine, 32:241-249.

[39] Courtney KL (2008). Privacy and senior willingness to adopt smart home information technology in residential care facilities. Methods of Information in Medicine, 47:76-81.

[40] Percival J, Hanson J (2006). Big brother or brave new world? Telecare and its implications for older people's independence and social inclusion. Critical Social Policy, 26: 888-909.

[41] Siotia R, Simpson C (2008). Applying telecare in dementia: What psychiatrists need to know. Advances in Psychiatric Treatment, 14: 382-388.

[42] Agich G. Dependence and autonomy in old age. Cambridge: Cambridge University Press; 2003.

[43] Hertogh CMPM (2004). Between autonomy and security: Ethical questions in the care of elderly persons with dementia in nursing homes. In: Jones GMM, Miesen BML, editors. Care-giving in Dementia. East Sussex: Brunner-Routledge, 375-390.

[44] Nishiguchi S, Yamada M, Nagai K, et al (2012). Reliability and validity of gait analysis by android-based smartphone. Telemedicine and e-Health, 18(4): 292-296.

[45] López-de-Ipiña K, Alonso JB, Travieso CM, et al (2013). On the selection of non-invasive methods based on speech analysis oriented to automatic Alzheimer Disease diagnosis. Sensors, 5: 6730-6745.

[46] López-de-Ipiña K, Alonso JB, Solé-Casals J, et al (2013). On Automatic Diagnosis of Alzheimer's disease Based on Spontaneous Speech Analysis and Emotional Temperature. Cognitive Computation, 7(1): 44-55. .

[47] López-de-Ipina K, Alonso, JB, Solé-Casals J, et al (2015). Feature selection for automatic analysis of emotional response based on nonlinear speech modeling suitable for diagnosis of Alzheimer's disease. Neurocomputing, 150: 392-401.

[48] López-de-Ipina K, Solé-Casals J, Eguiraun H, Alonso J.B, Travieso CM, Ezeiza A, Barroso N, Ecay-Torres M, Martinez-Lage P, Beitia B (2015). Feature selection for spontaneous speech analysis to aid in Alzheimer's disease diagnosis: A fractal dimension approach. Computer Speech \& Language, 30(1): 43-60.

[49] Faundez-Zanuy M, Sesa-Nogueras E, Roure-Alcobé J, Garré-Olmo J, Lopez-de-Ipiña K, Solé-Casals J (2013). 
Online Drawings for Dementia Diagnose: In-Air and Pressure Information Analysis. XIII Mediterranean Conference on Medical and Biological Engineering and Computing 2013 IFMBE. Proceedings Volume 41, 2014, pp 567-570.

[50] Drotar P, Mekyska J, Smekal Z, Rektorova I, Masarova L, Faundez-Zanuy M (2013). Prediction potential of different handwriting tasks for diagnosis of Parkinson's. The 4th IEEE International Conference on E-Health and Bioengineering - EHB 2013. E-Health and Bioengineering Conference (EHB).

[51] López-de-Ipina K, Iturrate M, Calvo PM, et al (2015). Selection of entropy based features for the analysis of the Archimedes' spiral applied to essential tremor. 4th International Work Conference on Bioinspired Intelligence (IWOBI), IEEE, 157-162.

[52] Link BG, Phelan JC (2006). Stigma and its public health implications. The Lancet, 367(9509): 528-529.

[53] Keusch GT, Wilentz J, Kleinman A (2006). Stigma and global health: developing a research agenda. The Lancet, 367(9509): 525-527.

[54] Lorig KR, Ritter PL, Laurent DD, Plant K (2006). Internet-based chronic disease self-management: A randomized trial. Medical Care, 44(11): 964-971.

[55] Nijland N, van Gemert-Pijnen J, Boer H, Steehouder MF, Seydel ER (2008). Evaluation of internet-based technology for supporting self-care: problems encountered by patients and caregivers when using selfcare applications. Journal of medical Internet research, 10(2): e13.

[56] O’Neill S, Brady RRW (2012). Colorectal smartphone apps: opportunities and risks. Colorectal Disease, 14(9): e530-e534.

[57] Albrecht UV (2013). Transparency of health-apps for trust and decision making. Journal of Medical Internet Research, 15(12): e277.

[58] Mallenius S, Rossi M,Tuunainen VK (2007). Factors affecting the adoption and use of mobile devices and services by elderly people-results from a pilot study. 6th Annual Global Mobility Roundtable, 31.

[59] Kurniawan S (2008). Older people and mobile phones: A multi-method investigation. International Journal of Human-Computer Studies, 66(12): 889-901.

[60] Ziefle M, Bay S (2005). How older adults meet complexity: aging effects on the usability of different mobile phones. Behaviour \& Information Technology, 24(5): 375-389.

[61] Bechtold U, Sotoudeh M (2013). Assistive technologies: Their development from a technology assessment perspective. Gerontechnology, 11(4): 521-533. 